\title{
Ciência e domínio da natureza: lições de um liuro clássico
}

\section{Science and domain of nature: lessons from a classic book}

\author{
Prof. Dr. Alberto Cupani - \\ UFSC \\ cupani.alberto@gmail.com
}

ORCID:

https://orcid.org/0000-0002$\underline{2812-7754}$

Recebido em: 14/04/2021

Aceito em: 18/05/2021

\section{Resumo}

No presente trabalho nosso fio condutor será a análise da obra The Domination of Nature de William Leiss. A afirmação central do livro, em grande medida seu leit motiv, é a de que a expressão "domínio da Natureza" é enganosamente óbvia. "Domínio", e seus equivalentes: "controle" e "conquista" (da Natureza) parecem ter - e haver tido, desde suas primeiras formulações - um sentido claro para todo mundo. No entanto, boa parte do trabalho do livro consiste em mostrar a ambiguidade, complexidade e mudança de significado dessa expressão, sendo necessário analisa-la para compreender rigorosamente seu verdadeiro papel histórico. A tese do autor é a de que a famosa divisa esconde, ao mesmo tempo que esclarece (digamos, enuncia) seu pretenso significado, e que ao exame cuidadoso revelam-se ambiguidades, contradições e premissas não manifestas.

Palavras chave: Natureza, técnica, tecnologia, conhecimento, poder.

\section{Abstract}

In the present paper our guiding thread will be the analysis of William Leiss's The Domination of Nature. The central claim of the book, and to a large extent its leit motiv, is that the expression "domination of Nature" is deceptively obvious. "Domination", and its equivalents: "control" and "conquest" (of Nature) seem to have - and have had, since their first formulations - a clear meaning for everyone. However, much of the work of the book consists in showing the ambiguity, complexity and changing meaning of this expression, and it is necessary to analyze it in order to rigorously understand its true historical role. The author's thesis is that the famous motto hides, while clarifying (say, enunciating) its purported meaning, and that upon careful examination reveals ambiguities, contradictions, and unmanifest premises.

Key words: Nature, technique, technology, knowledge, power. 
A atual pandemia, em que um vírus pôs em xeque a vida humana planetária sem que haja de momento vacina nem remédio seguro, mostrou que a Natureza não está dominada pela ciência e a tecnologia. A nossa situação parece reproduzir, em escala mundial, a catástrofe da Peste Negra, desmentindo a confiança (compartilhada tanto por intelectuais quanto por cidadãos comuns dos países industrializados) em que os recursos da civilização evitariam ou neutralizariam qualquer ameaça proveniente das forças naturais. A existência do homem ficaria à mercê apenas (!) das forças destrutivas de suas próprias criações (como em uma guerra nuclear) ou das consequências da sua atividade produtiva desenfreada (isto é, na alteração nociva do meio ambiente). A Natureza, após trezentos anos de pesquisa e manipulação, estaria completamente sob controle dos animais racionais.

Notoriamente, houve questionamentos dessa crença otimista desde as suas primeiras formulações por Bacon e Descartes, tanto no que tange à sua possibilidade quanto à sua conveniência, porém ela não parecia haver perdido o seu poder de sedução até chegarmos à presente calamidade. No entanto, um livro publicado há quase cinquenta anos havia alertado contra essa confiança, desmontando de maneira até hoje inigualada os seus alicerces. Refiro-me à The Domination of Nature, do cientista político norte-americano William Leiss (1939 -). ${ }^{1}$ Uma releitura dessa obra é, acredito, proveitosa em este momento. Ninguém sabe como será o mundo do futuro, passada de algum modo a presente conjuntura, mas entre outras mudanças, suspeito que a ciência e a tecnologia devam ser reformuladas. As teses de Leiss seriam úteis para tanto.

A afirmação central do livro, em grande medida seu leit motiv, é a de que a expressão "domínio da Natureza" é enganosamente óbvia. "Domínio", e seus equivalentes: "controle" e "conquista" (da Natureza) parecem ter - e haver tido, desde suas primeiras formulações - um sentido claro para todo mundo. ${ }^{2}$ No entanto, boa parte do trabalho do livro consiste em mostrar a ambiguidade, complexidade e mudança de significado dessa expressão, sendo necessário analisa-la para compreender rigorosamente seu verdadeiro papel histórico. A tese do autor é a de que a famosa divisa esconde, ao mesmo tempo que esclarece (digamos, enuncia) seu pretenso significado, e que ao exame cuidadoso revelam-se ambiguidades, contradições e premissas não manifestas. A divisa tem fontes múltiplas, constituindo uma sorte de "mosaico intelectual"” cujo sentido, além do mais, foi mudando desde o século XVII. Suas "dimensões totais", como veremos, ficam "obscurecidas".

Como propósito social, ela domina, certamente, a Idade Moderna e a caracteriza. Para a consciência histórica convencional, o homem ocidental, após séculos de submissão dolorosa a uma Natureza desconhecida (por mais que fosse amiúde reverenciada como "mãe"), ter-se-ia proposto subverter essa relação e passar, de dominado a dominador, mediante um recurso perfeitamente adequado à sua índole de "animal racional": o conhecimento correto das forças naturais. Não que o homem não tivesse antes nenhum conhecimento do ambiente; se assim fosse, não teria sobrevivido. Mas esse conhecimento era superficial e em boa parte ilusório, insuficiente para que permitisse superar as diversas formas de miséria humana: fome, doença, vulnerabilidade, trabalho exaustivo. Elevar a qualidade de vida mediante o verdadeiro saber: tal o propósito do homem moderno, formulado pelos seus arautos como Bacon e Descartes.

A famosa frase: "Saber é poder" parece consagrar Francis Bacon como o grande codificador da conquista da Natureza. ${ }^{4}$ No entanto, segundo Leiss a forma que o ideal adquiriu historicamente não corresponde exatamente à maneira em que o Grande Chanceler entendia a empreitada que queria estimular, embora suas ideias tenham preparado seu entendimento posterior. Isso porque, em Bacon, o domínio da Natureza não estava desvinculado do pano de fundo religioso. Ele teria separado a noção das "ilusões megalomaníacas" dos alquimistas e a tornado mais respeitável ao associá-la com o Cristianismo. Para ele, a religião e a ciência

1 Publicado originariamente em 1972, o livro foi reeditado em 1994 com um prólogo que atualizava suas teses (Montreal \& Kingston/London/ Buffalo: McGill-Queen's University Press. Especialista em questões ambientais, Leiss é autor de outros livros como Risk and Responsibility (1994), Under Technology's Thumb (1990) e The Limits to Satisfaction (1976).

2 Leiss prefere "mastery". O homem como "master" (senhor) da Natureza. (op. cit.,p. 120).

3 Salvo indicação em contrário, as aspas indicam sempre expressões de Leiss.

4 Descartes se expressou, como é sabido, em termos análogos, porém a ideia de domínio da Natureza não tem em sua filosofia a envergadura que alcança na obra de Bacon. 
estavam engajadas em um esforço mútuo para compensar o prejuízo causado pelo pecado original. A queda de Adão não teria se devido à sua incapacidade de dominar a Natureza mas à ambição de julgar moralmente ("conhecer o bem e o mal") e revoltar-se contra Deus. A recuperação do "estado de inocência" prévio à queda não se dava, para Bacon, pela ciência, mas pela religião. A ciência - pensava - não nos revela o plano de Deus para o mundo e o homem (ou seja, o conhecimento natural não iria ameaçar a fé). ${ }^{5}$ Mas a fórmula de Bacon permitiu que a ideia de domínio da Natureza se tornasse amplamente aceitável e fosse posteriormente secularizada quando a influência cultural da religião diminuiu (p. 49).

Leiss aponta raízes míticas, religiosas e filosóficas da ideia de domínio da Natureza. Quanto às origens míticas, Leiss observa (apoiando-se na obra de M. Eliade) que a fabricação de instrumentos a partir de metais sempre teve uma aura divina e certa conotação demoníaca, que se expressa nas lendas de diversas culturas e nos rituais para aplacar os deuses por ocasião de extrair e moldar metais. Os riscos de desafiar os limites naturais do homem (ilustrados na história de Dédalo e Ícaro) ${ }^{6}$ parecem acompanhar desde sempre a tentação de conquistar a Natureza, fazendo o até então impossível. Em todo caso, essas raízes míticas sinalizariam a presença de tendências ou consequências negativas que acompanhariam os esforços por controlar as forças naturais, e que o homem teme. O racionalismo encarnado na ciência e a tecnologia estaria acompanhado por um irracionalismo prestes a se desatar a qualquer instante. Isso explicaria o misto de fascínio e receio com que o homem comum percebe a tecnologia, espelhando-se nas histórias de ciência-ficção em que criaturas se revoltam contra seus criadores. Em resumo: desde suas origens míticas, a pretensão de conquistar a Natureza é um ideal ambivalente.

A raiz religiosa dessa pretensão está no Cristianismo, que faz do homem, único ser criado que compartilha do espírito do seu Criador, um "senhor da terra", por delegação divina. "Não há uma fonte original mais importante da ideia de domínio da Natureza"- escreve Leiss - que essa, presente tanto em teólogos católicos como Tomás de Aquino, quanto em Lutero. Leiss menciona a conhecida tese do historiador Lynn White, ${ }^{7}$ segundo a qual o relato bíblico seria a origem da atual crise ecológica, embora a retifique parcialmente. Ao negar o animismo, a tradição (judeu)cristã teria aberto o caminho para a ciência (cabe lembrar que a maioria dos cientistas do início da Modernidade tinha preocupações religiosas). Além do mais, o poder conferido ao homem sobre o restante dos seres criado seria absoluto (como base da correspondente soberania delegada). Para Leiss, essa analogia política domina o sentido do "controle" (da "conquista", do "domínio") da Natureza pelo ser humano. No entanto, e corrigindo White, Leiss observa que a Natureza tinha na tradição bíblica um duplo aspecto: como fonte de satisfação das necessidades humanas, e como testemunho da providência divina e seus planos. Por essa razão, a doutrina cristã fazia o homem responsável ante Deus pela sua conduta em relação à Natureza. Ou seja: a exploração da Natureza tinha limites éticos, que depois perdeu ao se identificar a dominação com o progresso científico-tecnológico e produzir-se o antagonismo da ciência e a religião.

Haveria para Leiss uma terceira raiz, especificamente filosófica, do ideal de dominar a Natureza, nos humanistas da Renascença, que às vezes retratavam o homem como um "macaco da Natureza", isto é, um imitador desta última. Com efeito, a Renascença foi um tempo de intenso interesse nos "secretos" e "tesouros" da Natureza, acompanhando uma crescente confiança na capacidade humana de expandir os limites da utilização das forças naturais. Nessa maré espiritual misturaram-se as práticas dos artesãos com as crenças místicas, vinculando diversas atividades: magia, alquimia, astrologia, até o "controle da fortuna" pregado por Machiavel. Tratou-se, argumenta Leiss, de influências "fragmentárias e difusas", mas que contribuíram para a aceitação do ideal que estamos analisando. Particularmente, a denominada magia "boa" ou "natural" (à diferença da magia demoníaca, condenada pela Igreja), que aspirava a manipular a Natureza obedecendo-a. ${ }^{8}$ Não menos importante teria sido o "fascínio dos números" que fazia parte dessa magia e ajudou a conceber uma ciência exata de base matemática.

5 A ciência e as artes eram para Bacon "moralmente inocentes", o que preparou o caminho para a noção da neutralidade da ciência, bem como para a separação entre fatos e valores, observa Leiss (p. 53-54).

6 E de Prometeu, poderíamos acrescentar.

7 "The Historical Roots of our Ecological Crisis", in Science, vol. 155, 1967.

8 Essa "obediência" teria se transformado, de um princípio moral em uma regra técnica da nova ciência. 
Segundo Leiss, a ideia de dominar a Natureza alcançou sua forma moderna no século XVII, época de grande atração pela ciência (depois, também pelas "artes mecânicas") por todos os intelectuais. Aos poucos, e devido aos seus triunfos, a ciência foi se separando da magia, a alquimia e a astrologia, e o Iluminismo viu nela o instrumento da felicidade humana. A ideia foi se consolidando, "ossificando", tornando-se óbvia, e perdendo relação com outras conotações que não fossem sua relação com o novo método científico. Para nosso autor não se pode afirmar que a noção de dominar a Natureza tenha sido o fator determinante da ciência, mas nos oferece um guia das motivações dos seus líderes, cuja influência acabou criando uma ideologia social poderosa

No entanto, uma vez estabelecida ela foi vista como a maneira pela qual o homem se apossa da Natureza, a completa e aperfeiçoa. ${ }^{9}$ Como é sabido, no século XIX a ciência e a tecnologia uniram-se sistematicamente à indústria. ${ }^{10}$

Tampouco acha Leiss que a ideia de dominar a Natureza tenha nascido do Capitalismo, embora "tenha se misturado muito bem com ele", e o triunfo do Capitalismo haja consolidado o triunfo da ciência sobre outros sistemas de filosofia natural. Para compreender essa combinação, Leiss aponta semelhanças entre ambos fenômenos históricos. O Capitalismo erode toda fundamentação "naturalista" ou pessoal do comportamento econômico tradicional, e o baseia nos imperativos abstratos do mercado, expandindo-se sobre domínios cada vez mais amplos. Também a ciência é universalista na sua finalidade, e tende igualmente a suprimir tudo quanto for pessoal ou cultural nas suas práticas. Ambos questionam as limitações que as circunstâncias podem opor às suas ambições. Ambos demandam que o interesse humano imediato seja suspenso ou anulado, de modo que o processo de desenvolvimento seja impulsionado por uma lógica interna. E para ambos, tudo isso serve aos interesses humanos em um plano mais elevado.

No seio do ideal em análise - continua afirmando Leiss - existe uma inter-relação de certos fenômenos históricos: a crescente compreensão científica das "leis da Natureza"11; o sucesso continuado de transformar as descobertas científicas em inovação tecnológica a um ritmo cada vez mais rápido; a habilidade, alcançada na Revolução Industrial, de aplicar a inovação tecnológica na produção massiva de bens; a esperança de que todas essas tendências reduziriam ou até eliminariam as origens habituais da miséria humana e a desordem social. Esta última expectativa não foi até hoje cumprida. Isso porque o ideal esconde, sob sua aparente obviedade, contradições sociais, e pressupõe que existe um vínculo (digamos, natural) entre o controle da Natureza e o autocontrole do ser humano, isto é, o controle dos impulsos destrutivos da condição humana.

Houve - interpreta Leiss - uma "astúcia da Razão" (Hegel) no desenvolvimento da "conquista" da Natureza como um vasto movimento que sintetizou inúmeros fatores e interesses, individuais e grupais. Ao mesmo tempo, as brilhantes promessas sociais desse sonho ficaram frustradas, como se uma "astúcia da sem-razão" (cunning of unreason) sabotasse o processo todo. ${ }^{12}$ A ciência, suposta protagonista desse domínio, pesquisa uma Natureza idealizada, constituída pelo que pode ser constatado "objetivamente", sendo impotente para operar no subjetivo "mundo-da-vida" (Husserl). Ela não pode transcender seu caráter de "saber de domínio" (Max Scheler) e fornecer diretrizes morais e políticas. ${ }^{13} \mathrm{~A}$ ciência moderna tem, argumenta Leiss, um caráter essencialmente instrumental, um caráter "tecnológico a priori", mas seu avanço resultou na posse de "meios cada vez mais eficientes para alcançar fins cada vez mais obscuros”. A ideia e o ideal de progresso, intimamente associado com o ideal de dominar a Natureza, é tão enganosamente óbvio como este último. Por isso, ambos os ideais foram guiando uma sociedade em que os conflitos sociais, longe de desaparecerem, se renovaram

9 Ela serviu também para justificar a conquista e colonização de outras partes do mundo, ao autorizar o domínio humano, não apenas sobre os animais mas também sobre aqueles outros congêneres que pareciam não haver alcançado o estatuto da humanidade (LEISS, p.74).

10 Apesar do seu triunfo, a ideia teria conservado até hoje, em nosso inconsciente, uma associação com o mal, a culpa e o medo, segundo Leiss (p. 44). Essa associação explicaria que amiúde a tecnologia seja ao mesmo tempo desejada e temida.

11 Posteriormente as "leis" do mercado foram reivindicadas como naturais.

12 Essa "astúcia" inclui a crença de que o empreendimento "domínio da Natureza" é, ele próprio, dominado (LEISS, p.23).

13 Leiss questiona Scheler por este último, tão perspicaz sobre o "saber de domínio", não ter-se perguntado pela diferença entre domínio técnico da Natureza e domínio prático dos homens (LEISS, p. 118-119). 
e exacerbaram. Sob a alegação de estar propiciando um mundo melhor para todos, a ciência e a tecnologia geraram uma sociedade em que a racionalidade instrumental triunfante oculta uma irracionalidade substancial (Horkheimer), pois a racionalidade científica não pode garantir a racionalidade social. Uma sociedade em que os meios de controlar a Natureza convertem-se cada vez mais em meios (por vezes violentos, por vezes subtis) de domínio de uns homens por outros e de domesticação da consciência individual. ${ }^{14}$ Isso não significa que o conflito tenha sido introduzido na existência humana pela ciência e a tecnologia: ele sempre existiu, pois faz parte da vida. O caráter ilusório da ideologia moderna consiste em presumir que a "conquista da Natureza" foi suprimindo-o.

Se as observações anteriores levam a pensar que o ideal que analisamos é exclusivo da sociedade capitalista, Leiss adverte que na verdade foi uma ideologia endossada por vários projetos políticos. "Foi, antes a suposição mais ou menos tácita de ideologias modernas com seus sistemas de explicita racionalização de conceptos tais como liberdade, [ou] justiça social, desenvolvimento econômico através das forças de mercado, imperialismo e privilégio de elites ou classes" (LEISS, p. xx). ${ }^{15}$

Significa isso que o ideal seja uma mera ideologia, que devamos descartar?

Não necessariamente. Leiss afirma que as ideologias podem ter um papel importante na promoção de uma sociedade mais justa e harmoniosa. A ideologia dos direitos humanos, por exemplo, foi uma poderosa ferramenta para superar a estruturas sociais precedentes e criar outras que protegessem o indivíduo. A ciência, como braço executor dessa ideologia, foi eficaz em desnaturalizar crenças e instituições que impediam a mudança social. O fato de que depois tenha se convertido em um véu que oculta a realidade de um mundo dividido em explorados e exploradores não anula seu papel positivo inicial nem sua possível reinterpretação. De maneira análoga, que a ideologia do domínio da Natureza funcione ainda hoje como justificativa da sociedade industrial, negando a desigual apropriação dos produtos desse domínio não significa que ela não possa ser reinterpretada para servir a uma afirmação universal do ser humano. Isso supõe, no pensamento do autor, certos esclarecimentos a mais. ${ }^{16}$

O domínio da Natureza não é um propósito da racionalidade científica por si mesma, mas uma "ampla tarefa social". A ciência, portanto, não pode ser reduzida ao seu papel nessa tarefa. Para Leiss, a ciência, igual que "outras formações culturais avançadas" como a arte, a religião e a filosofia, sem deixar de ter um conteúdo social, de algum modo transcendem a situação que as origina. ${ }^{17}$ É possível pensar numa ciência não subordinada ao papel social que a Modernidade lhe encomendou. Ainda que não adiantando os traços dessa ciência, nosso autor destaca que a racionalidade da ciência é diferente daquela da tecnologia, sendo esta última, propriamente, o instrumento de domínio. Nem é possível entender ambas as racionalidades como complementares. A tecnologia mostrou-se eficaz ao estender o domínio da Natureza ao domínio dos homens e da própria natureza humana individual. É necessário que a ciência forneça os meios de um diferente controle do ser humano: o de suas tendências destrutivas.

Para conceber uma ciência não subordinada ao ideal de domínio da Natureza, precisamos lembrar que a Natureza não é algo fixo, constantemente presente ao homem como um objeto, e que a sua "conquista" (?) não é uma questão puramente técnica. Agir sobre a Natureza muda a natureza humana (Marx) e a relação do homem com aquela. Isso implica a necessidade de um "jogo recíproco entre a inteligência e a Natureza", que substitua o atual "fatídica dialética de crescente poder e crescente conflito". Mas - para Leiss - a noção de uma ciência diferente não pode surgir de substituir um conceito filosófico da Natureza por um outro. Esse

14 Dominar, observa Leiss, só é possível, estritamente, em relação a homens, porque o domínio supõe que outra vontade se submeta (p. 122).

15 Tanto o comunismo soviético quanto o nacional-socialismo confiaram no domínio científico da Natureza (os segundo especializou-se na manipulação tecnológica das consciências, ao mesmo tempo que criticava as sociedades democráticas).

16 O mesmo pode ocorrer, segundo Leiss, com a consigna de "viver em harmonia com a Natureza", quando usada como mero slogan, embora possa ter um sentido positivo, admite, quando concebida nos moldes do "desenvolvimento sustentável" (p. 173).

17 Ao passo que a tecnologia tem, segundo ele, uma relação "muito mais direta" com o âmbito das necessidades humanas e dos conflitos sociais (p. 146). 
tipo de proposta é puramente abstrata e não pode melhorar a situação social. É necessário antes compreender que o progresso científico e o progresso ético são complementares, dependem um do outro. E que se os benefícios da ciência devem alcançar todos os seres humanos por igual, as instituições sociais devem ser reconstruídas. ${ }^{18}$ Precisamos, argumenta Leiss de "um conjunto de instituições em que a responsabilidade e a autoridade estejam distribuídas amplamente entre os cidadãos". Ela não pode estar confiada a uma minoria, se deve haver progresso moral na sociedade. ${ }^{19}$

A ciência é socialmente importante porque, hoje como ontem, desmascara as categorias de pensamento falsamente naturais, sendo assim um instrumento de liberação mental e progresso social. Não podemos subestimar seu valor, mas é necessário separar, como já foi dito, a ciência de seu compromisso com dominar a natureza. Também seria necessário compreender que uma ciência "livre de valores", pressupõe um valor: o daquele domínio de que deve ser separada. Além do mais, não deveria esperar-se que o modelo científico-natural sirva para compreender o mundo humano, porque se trata de um âmbito "essencialmente diferente". ${ }^{20}$ Leiss dá a entender (o ponto não é abordado claramente) que, assim redefinida, a ciência poderia e deveria ajudar ao autêntico domínio sobre o ser humano: o domínio sobre as suas "tendências destrutivas" já mencionadas, para que o homem possa conviver harmoniosamente com seus congêneres.

Quanto ao ideal de dominar a Natureza, Leiss refere-se, no prefacio da edição de 1994, a diferentes autores (P. Singer, A. Borgmann, P. Taylor, N. Evernden...) que, de um ou outro modo, propõem que a convicção de que a humanidade possa e deva exercer domínio absoluto sobre a restante Natureza em seu próprio benefício seja abandonada (p. xvi). Na medida em que esse ideal continue a frustrar as expectativas das massas - alerta Leiss - corre o risco de ser substituído por uma contra-ideologia perversa que prometa "outro caminho para a felicidade" (como ocorreu no Fascismo).

A análise de Leiss é, acredito, uma fonte de lições para nossa situação. Não pode superar-se um ideal sem compreendê-lo profundamente, o que exige entender suas origens e seu percurso histórico; também, sua complexidade e ambiguidade. Para tal entendimento contribui, magistralmente, seu livro. Ao mesmo tempo, como a superação de ilusões exige mudar as condições que as tornam necessárias (Marx), a obra aponta também para a necessidade de mudanças sociais e não apenas de novos modos de pensar a nossa vida e seu "nicho": a Natureza. Limito-me a dois comentários, deixando para o leitor aproveitar a riqueza de sugestões que o texto encerra e cuja leitura, obviamente, recomendo.

O primeiro refere-se à ideia de dominar a Natureza. Leiss lembra que Aldous Huxley qualificou-a de "absurda". Se não se revela absurda, a ideia perde, nas presentes circunstâncias, a sua aparência de plausibilidade. Em verdade, já diversos fenômenos, como os tsunamis, puderam ser lidos como uma ameaça da Natureza irritada com seus minúsculos, porém terrivelmente pretensiosos habitantes humanos. "Se eu quiser...", parecia ser a mensagem.

A noção de progresso associada à (suposta) conquista científico-tecnológica da Natureza, implicava que as condições de vida da humanidade estavam melhorando, em termos de diminuição de esforços desnecessários e sofrimento, e que essa melhoria ia alcançando aos poucos a todos os seres humanos. Se tal progresso incluía certo grau de prejuízo ou desperdício dos elementos naturais isso ocorria porque tais "externalidades" eram infelizmente inevitáveis. E se a universal melhoria das condições de vida não alcançava ainda a todos os homens, isso respondia à enorme dificuldade da tarefa e às forças contrárias (como o obscurantismo, ou as estruturas de poder anacrônicas) que, no entanto, seriam algum dia finalmente derrotadas. Na verdade, observa um crítico da ideia de progresso, "a maioria das novas tecnologias não estão direcionadas diretamente

18 A própria ciência como instituição incluída, podemos supor. Essa necessidade poderia ser percebida na impotência (ou falta de interesse) dos cientistas para influenciar os eventos sociais (p. 192). Pense-se na dificuldade de os cientistas imporem aos governos seus temores sobre o aquecimento global.

19 Leiss parece antecipar as reivindicações atuais de democratizar a ciência.

20 Para Leiss, a pretensão de que "um método particular" seja o único modo de alcançar conhecimento objetivo transforma a ciência em uma ideologia (p. 175). 
a superar importantes obstáculos em direção a uma melhoria da qualidade de vida. Antes, buscam expandir a produtividade econômica, a competitividade e a escolha do consumidor [...] O crescimento econômico torna-se um substitutivo do progresso [...] Mais ainda, a mudança tecnológica cria sempre perdedores tanto quanto ganhadores.... ${ }^{21}$ Face a esse engano, precisamos encarar a nossa relação com a Natureza como uma de defesa combinada com respeito. Não podemos, certamente, trocar afã de domínio por um retorno à originária submissão. Mais ainda, uma nova maneira de conceber essa (necessária) relação há de prescindir, acredito, de ambas as noções, trocando-as por outras. Sugiro - com óbvia cautela - que pensemos em laços como o da reverência e o cuidado. Ambos devem referir-se, em minha opinião, tanto à Natureza quanto a nós mesmos, pois a exploração insensata em que se transformou a pretensão de domínio ou controle fez com que descuidássemos também a nossa própria dignidade. Isso pode requerer que vejamos nossa relação com a Natureza como algo que se rege, não apenas pela razão, mas também pelo sentimento, pela empatia com os outros seres vivos; ${ }^{22}$ também, que aprendamos da maneira em que outras culturas (não "ocidentais" nem "modernas") vivem em e de seu ambiente.

E quanto à ciência, responsável, parcialmente, do ideal ora questionado? Ela é vista pelos leigos e pela maioria dos cientistas (suponho) como o modo de conhecer verdadeiramente a Natureza. Esse alegado conhecimento foi e continua sendo a base da confiança na tecnologia, presente e futura, na medida em que a ciência permite previsão e controle dos eventos. Os filósofos da ciência, no entanto, nos ensinam a sermos cautelosos no que tange à palavra verdade aplicada à ciência, e nos demonstram que a previsibilidade científico-tecnológica não é todo-poderosa. Também nos fazem ver que, em matéria de uso do conhecimento, nem a razão nem a justiça costumam prevalecer, perdendo geralmente para o interesse e o poder. De todo modo, faz parte da nossa tradição cultural a conviçção de que o aumento do saber, particularmente do científico, é algo intrinsecamente bom, que deve ser preservado e estimulado. Não raramente, essa convicção é vinculada com o provérbio bíblico: "A verdade os fará livres", o que parece reforçar a sua validade. No entanto, tampouco o significado dessa convicção é tão óbvio assim. Além de suscitar a questão acerca de qual verdade (ou tipo de verdade) está sendo invocada (no provérbio bíblico não se trata de qualquer verdade, mas da palavra divina), é duvidoso que saber a verdade sempre nos liberte ou sequer nos favoreça. Existem verdades que afligem, que desanimam, que assustam. E verdades perigosas. ${ }^{23} \mathrm{O}$ aumento incessante do conhecimento científico do mundo (vamos conceder que se trata da verdade sobre o mundo), é tão libertador assim? Ou, mais radicalmente, constitui um bem em si mesmo (como professa a tradição iluminista?). John Ziman, bom conhecedor da ciência e defensor de seu papel não instrumental na vida humana, reconheceu que "a noção de produzir conhecimento 'por si mesmo' [for its own sake] desafia uma análise lógica”. ${ }^{24}$ Vale dizer que a confiança no valor inerente do saber científico é um hábito social como qualquer outro. Devemos abandoná-lo? Acredito que a confiança no saber científico em matéria de fatos (de preferência a convicções ideológicas ou de senso comum) é uma aquisição irrenunciável da espécie humana. Acredito também que o crescimento do saber ("mais luz") é condição da sobrevivência e da qualidade de vida. Mas não se trata de qualquer tipo de ciência. É desejável uma ciência que, sem abandonar sua projeção tecnológica, não se reduza a ela, servindo tanto ao controle (responsável) do ambiente quanto ao melhor entendimento dos seres humanos e à superação de toda opressão (Habermas). ${ }^{25}$ Que seja abrangente e sistêmica ao enfocar qualquer assunto, em vez de pulverizar-se em especialidades. Que não desdenhe outros saberes, pois não podemos viver tão somente de ciência. E que assuma a condição ética de sua prática e seu caráter político (que não fica anulado por proclamar "a ciência pela ciência"), cuidando-se de funcionar como uma ideologia. Longa vida a uma ciência nova!

21 Daniel Sarewitz, "The Idea of Progress", in: Companion to the Philosophy of Technology. Ed. by J. K. B. O. Friss e outros. Chichester: Blackwell, 2013, p. 304.

22 É necessário apontar que o tratamento que dispensamos aos animais, daqueles "de estimação" (?) até aos sacrificados atrozmente para consumo mostra até que ponto somos insensíveis a eles?

23 As limitações da pesquisa biológica propostas na conferência de Asilomar (1975) o confirmam.

24 ZIMAN, J. (2002 [2000]) Real Science. What it is, and what it means. Cambridge: Cambridge U.P., p. 156. Cabe acrescentar que alguns autores sustentam que o controle da Natureza foi sempre o propósito não declarado da "ciência pura" (v. p.e. LACEY, H. Valores e atividade científica SP: ed. 34, 2008.).

25 Habermas, J. “Conhecimento e interesse”, in: Os Pensadores. SP: Abril Cultural, 1980. 
Alberto Cupani

\section{Referências Bibliográficas}

HABERMAS, Jurgen. “Conhecimento e interesse”, in: Os Pensadores. SP: Abril Cultural, 1980.

LACEY, Hugh. Valores e atividade científica SP: ed. 34, 2008.

LEISS, William. The Domination of Nature. McGill-Queens University Press, 1994.

SAREWITZ, Daniel. "The Idea of Progress", in: Companion to the Philosophy of Technology. Ed. by J. K. B. O. Friss et al. Chichester: Blackwell, 2013.

WHITE JR, L. "The Historical Roots of our Ecological Crisis", in Science, vol. 155, 1967.

ZIMAN, John. Real Science. What it is, and what it means. Cambridge: Cambridge U.P., 2002. 